\title{
Correction to: Differences in individual and environmental factors between cutaneous melanoma and atypical Spitz tumour in children and adolescents
}

\author{
Cristina Fortes ${ }^{1}\left[\right.$. Simona Mastroeni ${ }^{1} \cdot$ Maria Capuano $^{2} \cdot$ Ilaria Ricozzi $^{1} \cdot$ Riccardo Bono $^{1} \cdot$ Francesco Ricci $^{1}$. \\ Gianluca Pagnanelli ${ }^{1} \cdot$ Maurizio Nudo ${ }^{3}$
}

Published online: 30 October 2021

(c) Springer-Verlag GmbH Germany, part of Springer Nature 2021

\section{Correction to: European Journal of Pediatrics} https://doi.org/10.1007/s00431-021-04204-x

In the original published version of this article, the authors' Given names and Family names where presented incorrectly. The names are now presented correctly above.

The original article has been corrected.

Publisher's Note Springer Nature remains neutral with regard to jurisdictional claims in published maps and institutional affiliations.

The original article can be found online at https://doi.org/10.1007/ s00431-021-04204-x

Cristina Fortes

c.fortes@idi.it

Simona Mastroeni

s.mastroeni@idi.it

Maria Capuano

m.capuano@idi.it

Ilaria Ricozzi

ilariaricozzi@gmail.com

Riccardo Bono

bonoriccardo@gmail.com

Francesco Ricci

F.Ricci@idi.it
Gianluca Pagnanelli

G.Pagnanelli@idi.it

Maurizio Nudo

nudomaurizio@gmail.com

1 Istituto Dermopatico Dell'Immacolata Concezione, IDIIRCCS, Rome, Italy

2 Istituto Dermopatico Dell'Immacolata Concezione, IDI-IRCCS, Capranica, Viterbo, Italy

3 Dermatology Department, Humanitas Castelli, Bergamo, Italy 